\title{
Design and Implementation of a Pneumatic Servo System using Conventional Direction Control Valve
}

\author{
Amer Abed Mansour ${ }^{1}$, Walaa Mousa Hashim ${ }^{2}$, Abbas Abdul Wahab Muhammad ${ }^{3}$ \\ ${ }^{1,3}$ Department of Control and System Engineering/ University of Technology. Baghdad, Iraq \\ ${ }^{2}$ Department of Electromechanical Engineering/University of Technology. Baghdad, Iraq \\ ameralmesaody@yahoo.com,drawalaamousa@yahoo.com,ali1998abb@gmail.com
}

\begin{abstract}
Pneumatic servo systems are widely used in industrial applications but they are expensive, so decreasing their cost contribute in decreasing products manufacturing cost. In this research a pneumatic servo system (PSS) was designed and implemented using cheap conventional directional control valve $(C D C V)$ instead of expensive servo or proportional valves. The CDCV was driven using pulse width modulation (PWM) technique, which was generated in the LabVIEW program and send to the CDCV via Arduino uno microcontroller board. A fuzzy PI controller was designed and implemented to overcome the nonlinearity inherent in air systems, resulting from air compressibility and dry friction, and the nonlinearity resulting from the use of a $C D C V$ which is a digital valve. It is found that getting acceptable results require using PWM technique with frequencies greater than $90 \mathrm{~Hz}$. The results showed that increasing the applied pressure leads to a significant decrease in the rising time but accompanied with a noticeable increase in the ripple amplitude. So, getting accepted results require choosing the applied pressure experimentally to suit the applied load, since they are affected by the applied load.
\end{abstract}

Index Terms - Pneumatic servo system, Sequencer, conventional directional control valve.

\section{Introduction}

It is well known that the pneumatic actuators have characterized as having a reasonable cost which can be offered better choices to electric or hydraulic systems for many applications. In fact, there are several advantages of pneumatic actuators such as clean and inflammable, no generate magnetic fields, ease of maintenance, as well as offer a high ratio of power to weight. Besides, the pneumatic energy is existing in most industrial applications. Regardless of these facts, pneumatic actuators applications are poorly used in where accurate position control is needed, like welding machines, robotic and fluid injection. Due to the great nonlinearity of pneumatic systems behavior that makes them therefore a mathematical model and controls it is very difficult to makes.

J. Falcao Carneiro et.al [1], introduce a new controller pneumatic servo system in which obtain accurate performance in trajectory resulting errands. From the neural network based model, novel control design was developed from control of components motion and division controller of force. The performance controller design was subsequently examine in an experimental apparatus using servopneumatic components of standard industrial. Experimental results shown that a sinusoidal position with respect to frequency variation can be followed, for frequencies up to $\pi \operatorname{rads}^{-1}$, with errors of only a few millimeters.

B. Varseveld and M. Bone [2], examined design with open-loop system, involve hardware design and controller output signal. The development modeling was analytically described and hence controller design. Then the control method performance is investigated experimentally. control position was 
successfully applied using on-off solenoid valves. A comparison between standard PWM and novel PWM techniques of the open- and closed-loop responses shows that there has been a significant enhancement in the control.

S. Hodgson et.al [3], investigated a sliding-mode control arrangement for the open-loop system depend equivalent model has an averaged continuous input, a PSS designed and implemented using a conventional directional control valve (CDCV). The model was developed the dynamics nonlinear of open-loop with discontinuous-input system undergoing PWM of the input (i.e., on/off action). The results showed reducing in error position and active switching valve for the actuator.

A new control system design method was proposed by M. Hirano et.al [4]. This study was assumed the transfer function of the pneumatic servo system to be a fifth-order time lag system by dealing with the dynamic characteristics of servo valve as a second-order time lag system explicitly. It was found that the method can be utilized to choose the control parameters accurately without the need for a trial-and-error process. Additionally, the proportional gain obtained by the proposed method is larger than that obtained by the conventional method through trial and error and is near maximum in the stable region.

J. Falcao Carneiro and F. Gomes de Almeida [5], designed a new servopneumatic system model principally that developed for control tasks, specifically in order to expect forces in dynamic tests like pneumatic and friction forces. The model can also be utilise in simulation to detrmine the position and velocity of the piston. To validate the performance on both cases experimentally test was done; a results showed a good agreement was found between numerical simulation and experimental.

S. Riachy and M. Ghanes [6], inspected pneumatic cylinder control without pressure measurement. Depend on the homogeneous theory, limited steady time, state feedback nonlinear controller with ordinary differential equations, which was critically suggested, the closed loop circuit stability was verified and an attraction field of the controller was specified. a pneumatic actuator controlled using dSPACE dS1103 microcontroller an experimental setup while the performance and the effectiveness of the proposed controller were illustrated.

M.Smaoui et.al [7], revealed a model of a nonlinear controller in an electropneumatic system. Nonlinear back stepping control and nonlinear sliding mode control laws was implemented to the system under concern, acceptable control performance has been gained by both the back stepping and sliding-mode controllers. phenomenon chattering does not exist in the back stepping controller. So, the back stepping controller is more appropriate to control an electropneumatic system.

X. Shen et.al [8], presented a control style that allows nonlinear model-built control of pulse width modulated (PWM) servopneumatic actuators. A dynamics nonlinear of a PWM controlled to define the equivalent continuous-time and scheme an intermediate approach has been developed, which renders the system, the pneumatic actuator was converted into its intermediate corresponding control canonical shape and a sliding mode controller was developed based on the resulting test. The suggested controller was applied on an experimental apparatus and presented via the resulting tracking act to offer active control of a continuous motion control.

On the other hand, inexpensive digital valves were successfully implemented by H. Fawaz et.al [9], to position control of a pneumatic actuator utilizing pulse width modulation (PWM) method. A fuzzy PI controller was designed and applied to predomination the nonlinearity inherited in the system due to air compressibility, friction losses and the nature of the digital signal valves, it's clear that PWM is an low-cost and acceptable technique for position control of actuators by digital signal valves and fuzzy PI controller is satisfactory for exact pneumatic actuator position control. A PSS was critically designed and implemented using a conventional directional control valve (CDCV), which results a low cost pneumatic servo system. The pulse width modulation method will be used to drive the CDCV. 


\section{Theoretical Analysis}

The study is to derive mathematical models for each component of the pneumatic systems used with the assumptions required for each derivation of conventional pneumatic systems. For the mathematical model to represent as closely as possible a real physical one

\section{A. Mass Flow Rate Model [10]}

The flow has to be considered as compressible and turbulent due to pressure gradient in the orifice valve is usually large. The flow will considered as sonic velocity in which depend linearly on the upstream pressure if the upstream to downstream pressure ratio is larger than a critical value $P_{c r}$. While whene smaller than $P_{c r}$ the mass flow rate are nonlinearly on both pressures. The equation in which govern the mass flow rate through an area $A_{v}$ is

$$
\begin{gathered}
\dot{m}_{v}= \begin{cases}C_{f} * A_{v} * C_{1} * \frac{P_{u}}{\sqrt{T}} & \text { if } \frac{P d}{P u} \leq P_{c r} \\
C_{f} * A_{v} * C_{2} * \frac{P_{u}}{\sqrt{T}}\left(\frac{P_{d}}{P_{u}}\right)^{\frac{1}{k}} \sqrt{1-\left(\frac{P_{d}}{P_{u}}\right)^{(k-1) / k}} & \text { if } \frac{P d}{P u}>P_{c r}\end{cases} \\
C_{1}=\sqrt{\frac{K}{R}\left(\frac{2}{K+1}\right)^{\frac{K+1}{K-1}} \quad ; \quad C_{2}=\sqrt{\frac{2 K}{R(K-1)}} ; \quad P_{c r}=\left(\frac{2}{K+1}\right)^{\frac{K}{K-1}}, A_{v}: \text { valve area }}
\end{gathered}
$$

Where: $k=1.4, \quad C_{1}=0.040418, \quad C_{2}=0.156174$, and $P_{c r}=0.528, \mathrm{~T}=300 \mathrm{~K}, C_{f}=0.25[14]$

$$
\begin{gathered}
A_{v}=d^{2} * \frac{\pi}{4}=\left(8 * 10^{-3}\right)^{2} * \frac{\pi}{4}=5.02 * 10^{-5} m^{2} \\
\dot{m}_{v}= \begin{cases}34.43 * 10^{-9} * P_{u} & \text { if } \frac{P d}{P u} \leq 0.528 \\
133 * 10^{-9} * P_{u} *\left(\frac{P_{d}}{P_{u}}\right)^{0.714} \sqrt{1-\left(\frac{P_{d}}{P_{u}}\right)^{0.285}} & \text { if } \frac{P d}{P u}>0.528\end{cases}
\end{gathered}
$$

For extended stroke to calculate $\dot{m}_{v i n}, P_{u}=P_{s} \& P_{d}=P_{1}$ and $\dot{m}_{v o u t}, P_{u}=P_{2} \& \quad P_{d}=P_{a}$ while in retract for $\dot{m}_{v i n}, P_{u}=P_{s} \& P_{d}=P_{2}$ for $\dot{m}_{v o u t}, P_{u}=P_{1} \& P_{d}=P_{a}$

\section{B. Cylinder Chambers Model:}

For cylinder chamber1 [11]

$$
\dot{P}_{I}=\frac{R T}{V_{o 1}+A_{1} x}\left(\dot{m}_{\text {in }} \alpha_{\text {in }}-\dot{m}_{\text {out }} \alpha_{\text {out }}\right)-\alpha \frac{ \pm A_{1} P_{1}}{V_{o 1}+A_{1} x} \dot{x}
$$

Where $\alpha$ is thermodynamic process index.

Active length for side $1 \mathrm{~L}=0.1 \mathrm{~m}$, active area for side $1 A_{1}=1.9^{*} 10^{-3} \mathrm{~m}^{2}$, Inactive volume for side $1 V_{o 1}=9 * 10^{-5} \mathrm{~m}^{3}$, ambient temperature $T=300 \mathrm{k}$

Gas constant $R=287 \mathrm{~J} / \mathrm{kg} . \mathrm{k}, \alpha_{\text {in }}=1.4, \alpha_{\text {out }}=1, \alpha=1.2$, the model is simplified to follow form:

$$
\dot{P}_{1}=\frac{86100}{0.9 * 10^{-6}+1.9 * 10^{-3} * x}\left(1.4 * \dot{m}_{\text {in }}-\dot{m}_{\text {out }}\right)-1.2 \frac{ \pm 1.9 * 10^{-3} * P_{1}}{0.9 * 10^{-6}+1.9 * 10^{-3} * x} \dot{x}
$$

In which for extending

$$
\dot{P}_{1}=\frac{86100}{0.9 * 10^{-6}+1.9 * 10^{-3} * x}\left(1.4 * \dot{m}_{\text {in }}-\dot{m}_{\text {out }}\right)-1.2 \frac{1.9 * 10^{-3} * P_{1}}{0.9 * 10^{-6}+1.9 * 10^{-3} * x} \dot{x}
$$

And for retract

$$
\dot{P}_{1}=\frac{86100}{0.9 * 10^{-6}+1.9 * 10^{-3} * x}\left(1.4 * \dot{m}_{\text {in }}-\dot{m}_{\text {out }}\right)+1.2 \frac{1.9 * 10^{-3} * P_{1}}{0.9 * 10^{-6}+1.9 * 10^{-3} * x} \dot{x}
$$

And for cylinder chamber 2

$$
\dot{P}_{2}=\frac{R T}{V_{o 2}+A_{2}(L-x)}\left(\dot{m}_{\text {in }} \alpha_{\text {in }}-\dot{m}_{\text {out }} \alpha_{\text {out }}\right)-\alpha \frac{ \pm A_{2} P_{2}}{V_{o 2}+A_{2}(L-x)} \dot{x}
$$


Substitute active length for side $2, L=0.1 \mathrm{~m}$, active area for side $1 A_{2}=0.3^{*} 10^{-3} \mathrm{~m}^{2}$, inactive volume for side1 $V_{o 2}=5^{*} 10^{-5} \mathrm{~m}^{3}$, ambient temperature $T=300 \mathrm{k}$, Gas constant $R=287 \mathrm{~J} / \mathrm{kg} . \mathrm{k} \quad, \alpha_{i n}=1.4, \alpha_{\text {out }}=1$ , $\alpha=1.2$ we get

For extend

$$
\dot{P}_{2}=\frac{86100}{0.5 * 10^{-6}+0.3 * 10^{-3}(0.1-x)}\left(1.4 * \dot{m}_{\text {in }}-\dot{m}_{\text {out }}\right)+1.2 \frac{0.3 * 10^{-3} * P_{2}}{0.5 * 10^{-6}+0.3 * 10^{-3}(0.1-x)} \dot{x}
$$

For retract

$$
\dot{P}_{2}=\frac{86100}{0.5 * 10^{-6}+0.3 * 10^{-3}(0.1-x)}\left(1.4 * \dot{m}_{\text {in }}-\dot{m}_{\text {out }}\right)-1.2 \frac{0.3 * 10^{-3} * P_{2}}{0.5 * 10^{-6}+0.3 * 10^{-3}(0.1-x)} \dot{x}
$$

\section{Piston-Load Dynamics Model [12]}

For piston-rod assembly the equation of motion as shown in Figure 1 can be expressed as by applying Newton's second law,

$$
\begin{gathered}
M \ddot{x}+F_{f}=P_{1} \cdot A_{1}-P_{2} \cdot A_{2}-P_{a} \cdot A_{r} \\
\ddot{x}=\frac{1}{M}\left(P_{1} \cdot A_{1}-P_{2} \cdot A_{2}-P_{a} \cdot A_{r}-F_{f}\right)
\end{gathered}
$$

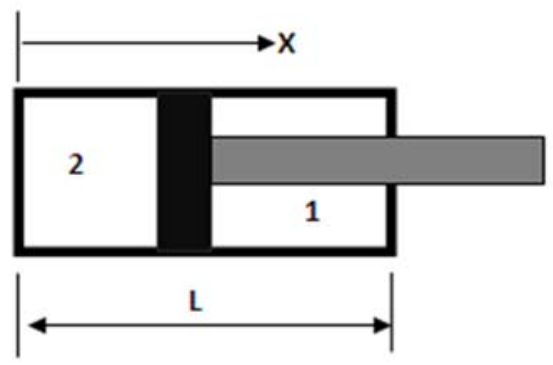

Fig.1. Singl Rod Doubl Acting

Fleischer [12] gives as a rule of thumb, the following equations for static and dynamic friction:

$$
F_{\text {static }}=0.67 \frac{\mathrm{N}}{\mathrm{mm}} \cdot d_{\text {bore }} \quad, \quad F_{\text {dynamic }}=0.4 \frac{\mathrm{N}}{\mathrm{mm}} \cdot d_{\text {bore }}
$$

For $d_{\text {bore }}=0.025 \mathrm{~m}, F_{\text {static }}$ and $F_{\text {dynamic }}$ are (33.5 and 20) N respectively, Actuator cross-sectional area side $1 A_{1}=1.9 * 10^{-3} \mathrm{~m}^{2}$.

Actuator cross-sectional area for side $1 A_{2}=A_{1}-A_{r}=1.96 * 10^{-3}-0.3 * 10^{-3}=1.646 * 10^{-3} \mathrm{~m}^{2}$, mass piston \& $\operatorname{rod} \&$ load assembly $=0.3 \mathrm{~kg}$.

By neglecting atmospheric force acting on the piston $\operatorname{rod}\left(P_{a} A_{r}\right)$ the model is simplified to follow form in start motion:

$\ddot{x}=\frac{1}{0.3}\left(4.9 * 10^{-4} * P_{1}-0.78 * 10^{-4} * P_{2}-26.75\right)$

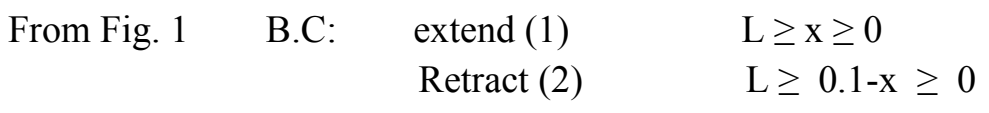

TABle 1. Nomenclature

\begin{tabular}{lcl}
\hline Symbol & Parameter & Units \\
\hline $\mathrm{A}_{1}$ & Extend effective area & $\mathrm{m}^{2}$ \\
$\mathrm{~A}_{2}$ & Retract effective area & $\mathrm{m}^{2}$ \\
$\mathrm{~A}_{\text {vin }}$ & Valve effective areas for input & $\mathrm{m}^{2}$ \\
$\mathrm{~A}_{\text {vex }}$ & Valve effective areas for exhaust & $\mathrm{m}^{2}$ \\
$\mathrm{C}$ & Orifice flow coefficient &
\end{tabular}




\begin{tabular}{lcc}
$\mathrm{C}_{1}, \mathrm{C}_{2}$ & Constants & - \\
$\mathrm{C}_{\mathrm{f}}$ & Discharge coefficient & - \\
$d_{\text {bore }}$ & Inlet \&outlet air cylinder diameter & $\mathrm{m}$ \\
$\mathrm{F}_{\mathrm{f}}$ & Total friction force in air cylinder & $\mathrm{N}$ \\
$\mathrm{L}$ & Air cylinder piston stroke & $\mathrm{m}$ \\
$\mathrm{m}$ & Air mass in cylinder & $\mathrm{kg}$ \\
$\mathrm{M}$ & Total piston mass & $\mathrm{Kg}$ \\
$\mathrm{P}$ & Air pressure & $\mathrm{bar}$ \\
$\mathrm{P} 1$ & Absolute pressure in extend & $\mathrm{bar}$ \\
$\mathrm{P} 2$ & Absolute pressure in retract & $\mathrm{bar}$ \\
$\mathrm{Pa}$ & Absolute ambient pressure & $\mathrm{bar}$ \\
$\mathrm{Pd}$ & Valve downstream pressure & $\mathrm{bar}$ \\
$\mathrm{Pu}$ & Valve upstream pressure & $\mathrm{bar}$ \\
$\mathrm{Pcr}$ & Critical pressure & $\mathrm{bar}$ \\
$\mathrm{R}$ & Gas constant & $\mathrm{j} / \mathrm{kg} \cdot \mathrm{k}$ \\
$\mathrm{T}$ & Absolute air temperature & $\mathrm{k}$ \\
$\mathrm{u}$ & Air velocity & $\mathrm{m} / \mathrm{s}$ \\
$\mathrm{V}$ oi & Inactive volume at the end stroke & $\mathrm{m}^{3}$ \\
$\mathrm{x}$ & Air cylinder piston displacement & $\mathrm{m}$ \\
$\mathrm{k}$ & Ratio of specific heats & - \\
$\boldsymbol{\rho}$ & Air density & $\mathrm{kg} / \mathrm{m}^{3}$ \\
$\alpha$ & Thermodynamic process index & - \\
\hline
\end{tabular}

\section{Experimental System Set-up}

The pneumatic rig shown in Figure. 2 and 3 explains the designed and implemented PSS using a CDCV. The pneumatic rig was built in the laboratory of Post Graduate Studies in Department of Control and Systems Engineering at the University of Technology. It involve of two main parts, electric and pneumatic portion. Electric part contains of PC, data acquisition and control unit, amplifier, potentiometer, and pneumatic part involves of the components for system, such as actuator, valves, tubes and other accessories.

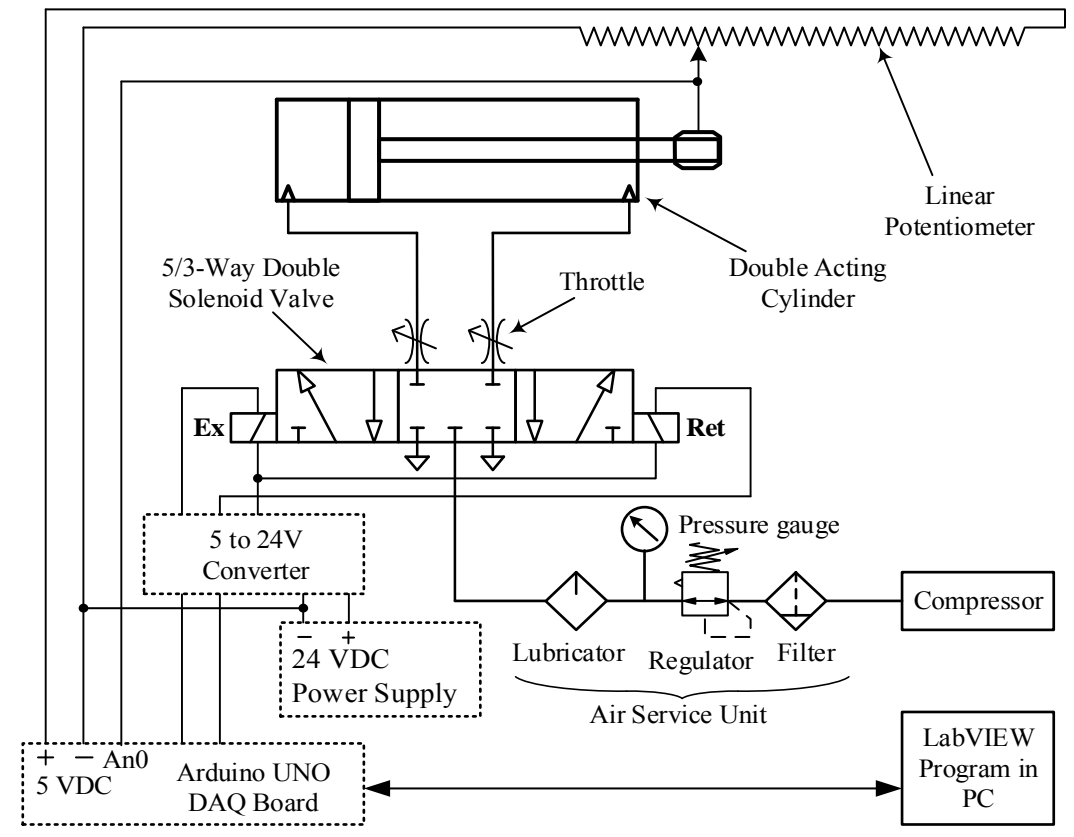

Fig.2. EXPERIMENTAL SETUP SCHEMATIC 


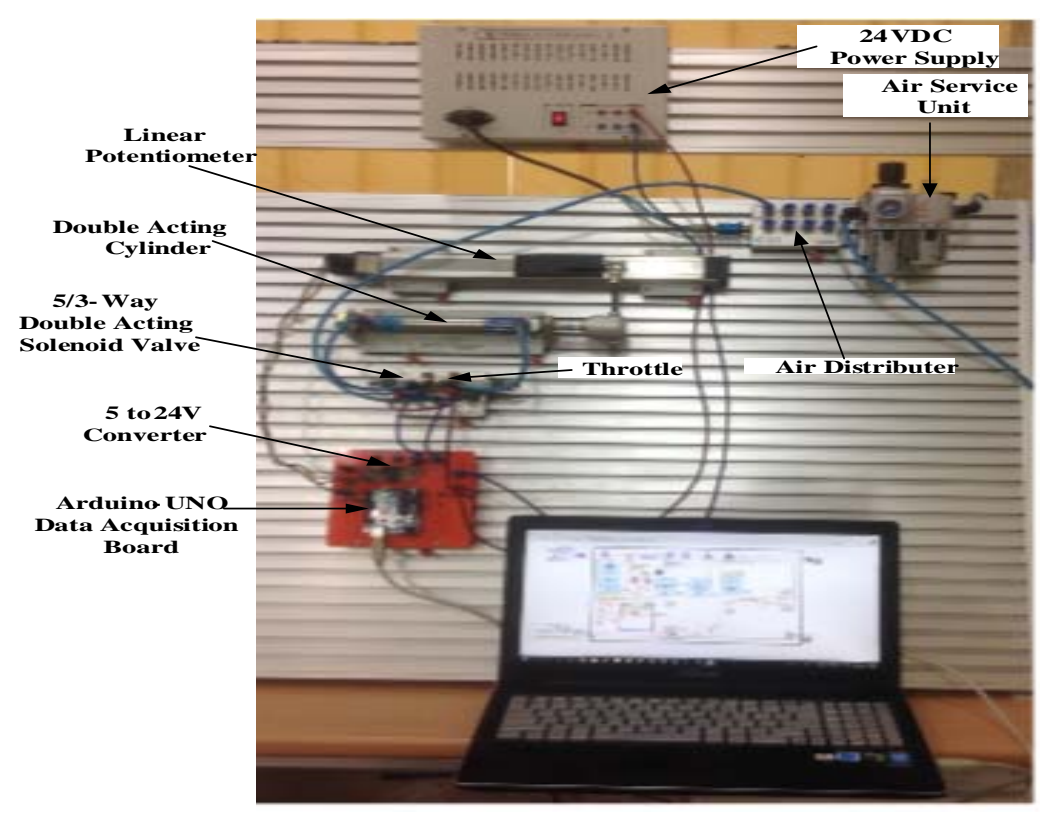

FIg.3. EXPERIMENTAL Rig

\section{A. Air Distributor}

Operating rating pressure $0 \sim 9 \mathrm{kgf} / \mathrm{cm}^{2}$, output port 8 inch , Input connector port 1 inch and $3 / 2$ way valve mounted to open/close supplied air.

\section{B. Air Service Unit}

Operating rating pressure: $0 \sim 9.9 \mathrm{kgf} / \mathrm{cm}^{2}$, fixed pressure $0.5 \sim 8.5 \mathrm{kgf} / \mathrm{cm}^{2}$ with air filter, pressure relief valve and automatic lubricator $10 \mu \mathrm{m}$ lubricant.

\section{Air Cylinder}

Single rod Double acting cylinder, operating rating Pressure $0.5 \sim 9.9 \mathrm{kgf} / \mathrm{cm}^{2}$, inner and rod diameter $25 \mathrm{~mm}, 10 \mathrm{~mm}$ respectively, stroke length $125 \mathrm{~mm}$, cylinder output $290 \mathrm{~N}$, cylinder return force $242 \mathrm{~N}$.

\section{Directional Control Valve}

A 5/3-way normally closed with spring return and solenoid operation, operating rating pressure $2.0 \sim 7.1 \mathrm{kgf} / \mathrm{cm}^{2}$, response time less than $32 \mathrm{~ms}$, electric power, $1.0 \mathrm{~W}-24 \mathrm{VDC}-41 \mathrm{~mA}$, non-polarity type with lamp solenoid coil and surge voltage protective circuit also can be operated manually.

\section{E. Linear Potentiometer}

Festo MLO - POT - 225 - TLF 152625002580 / 049313 / E, design resolution $0.01 \mathrm{~mm}$, max. speed $10 \mathrm{~m} / \mathrm{s}$, max acceleration $200 \mathrm{~m} / \mathrm{s}^{2}$, ball coupling angle offset $\pm 1^{\circ}$, parallel offset $\pm 1.5 \mathrm{~mm}$, service life $10^{6}$ strokes, 4-pin plug and weight $900 \mathrm{~g}$.

\section{F. Arduino Uno}

The Arduino Uno is a microcontroller board based on the ATmega328. Microcontroller ATmega 328 , operating rate voltage $5 \mathrm{~V}$ with input voltage $7-12 \mathrm{~V}$ and input voltage limits voltage $6-20 \mathrm{~V}$, digital I/O 14, six Pins with analog input and I/O Pin $40 \mathrm{~mA}$ DC current, DC current $3.3 \mathrm{~V}$ and $50 \mathrm{~mA}$, capacity $32 \mathrm{~KB}$ and clock speed $16 \mathrm{MHz}$.

\section{System Software (LabVIEW Program)}

Figure.4 shows the fuzzy PI controller structure, where the actual position is measured by the position sensor and subtracted from the set point to calculate the error. Error and derivative of error are fuzzified according to input variable membership functions shown in Figure.5, where triangle 
membership functions were used for small and medium error and trapezoid membership function for big error. These inputs are manipulated according to the control rules which is explained in Figure.6, where the center of the area defuzzification method was used, and then the consequent output variable membership functions are shown in Figure.7. Figure. 8 shows the whole transform characteristic curve of the fuzzy controller.

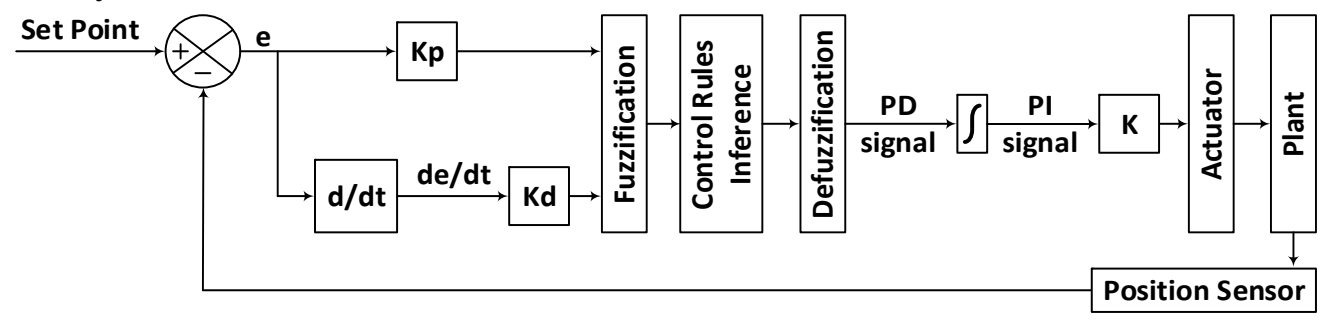

Fig.4. Fuzzy Pi CONTROLler StRuCTURE

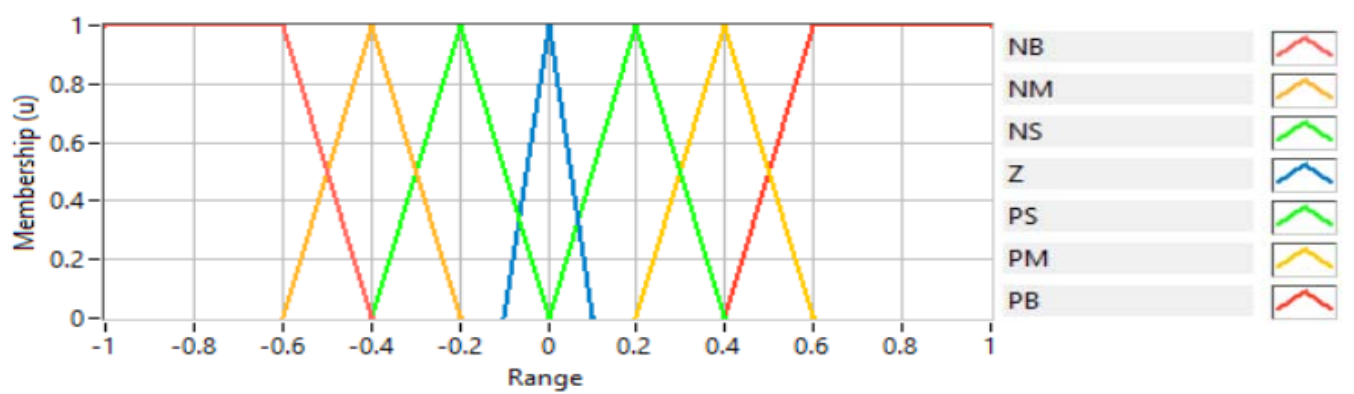

Fig.5. INPUT VARIABLE MEMBERSHIP FunCTIONS

\begin{tabular}{|c|c|c|c|c|c|c|c|}
\hline E dE & NB & NM & NS & $Z$ & PS & PM & PB \\
\hline NB & PB & PB & PM & PM & PS & PS & $Z$ \\
\hline NM & PB & PM & PM & PS & PS & $Z$ & NS \\
\hline NS & PM & PM & PS & PS & Z & Z & NS \\
\hline Z & PM & PS & PS & Z & NS & NS & NM \\
\hline PS & PS & Z & Z & NS & NS & NM & NM \\
\hline PM & PS & $Z$ & NS & NS & NM & NM & NB \\
\hline PB & $Z$ & NS & NS & NM & NM & NB & NB \\
\hline
\end{tabular}

FIG.6. FUZZY RULES

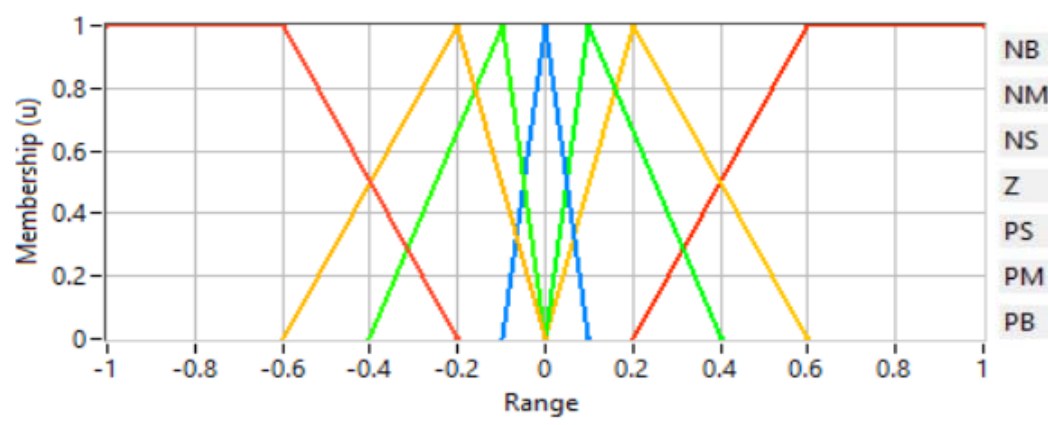

FIG.7. OUtPut VARIABLE MEMBERShip Functions 


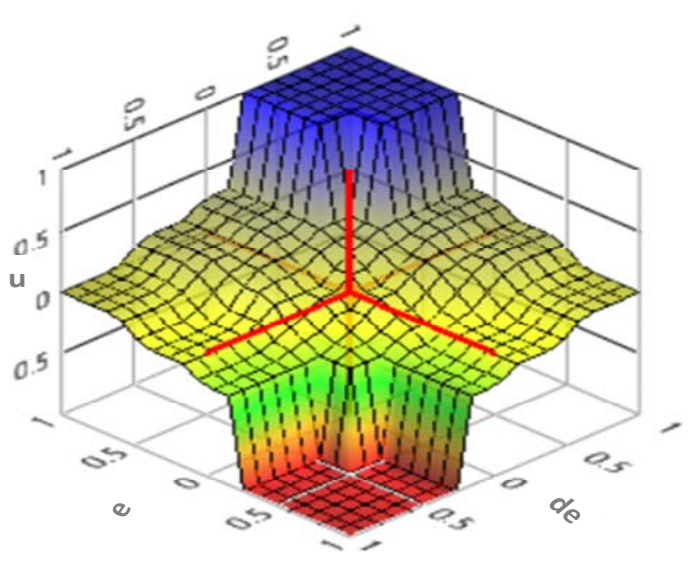

Fig.8. System InPUT / OUtPut RELATIONSHIP

Referring to Figur-9, the LabVIEW program receives the position value from the Arduino via USB to serial cable as a number between 0 and 1023. This number was modified by the mathematical formula block to be between 0 and $100 \mathrm{~mm}$ which is equivalent to 0 to full stroke of the pneumatic cylinder. A square set point signal is generated by the simulate signal block with $0.1 \mathrm{~Hz}, 15$ to $85 \mathrm{~mm}$ up/down limits. This allows the set point to be changed each $5 \mathrm{sec}$ as a step function from $15 \mathrm{~mm}$ to $85 \mathrm{~mm}$ and vice versa. The present value is subtracted from the generated set point to get the error. This error is multiplied by 0.01 to convert its range to be $0 \sim 1$ and then this error is differentiated by the derivative block. The error and its derivative are multiplied by the proportional gain $(\mathrm{Kp})$ and derivative gain $(\mathrm{Kd})$ respectively, and entered to case structure in order to build an array which is send to the fuzzy logic controller to get a fuzzy PD control signal. The fuzzy PD control signal is integrated by the integral block to get the fuzzy PI control signal which is multiplied by the gain $(\mathrm{K})$ and is sent to logic block to differentiate between the -ve and +ve action. The resulting signals then compared with the saw tooth signal that is generated by the simulate signal block to generate pulse modulated by the PI control signal. These signals then send to the 2/3-way double solenoid valve via the Arduino through 0 to $24 \mathrm{~V}$ converter.

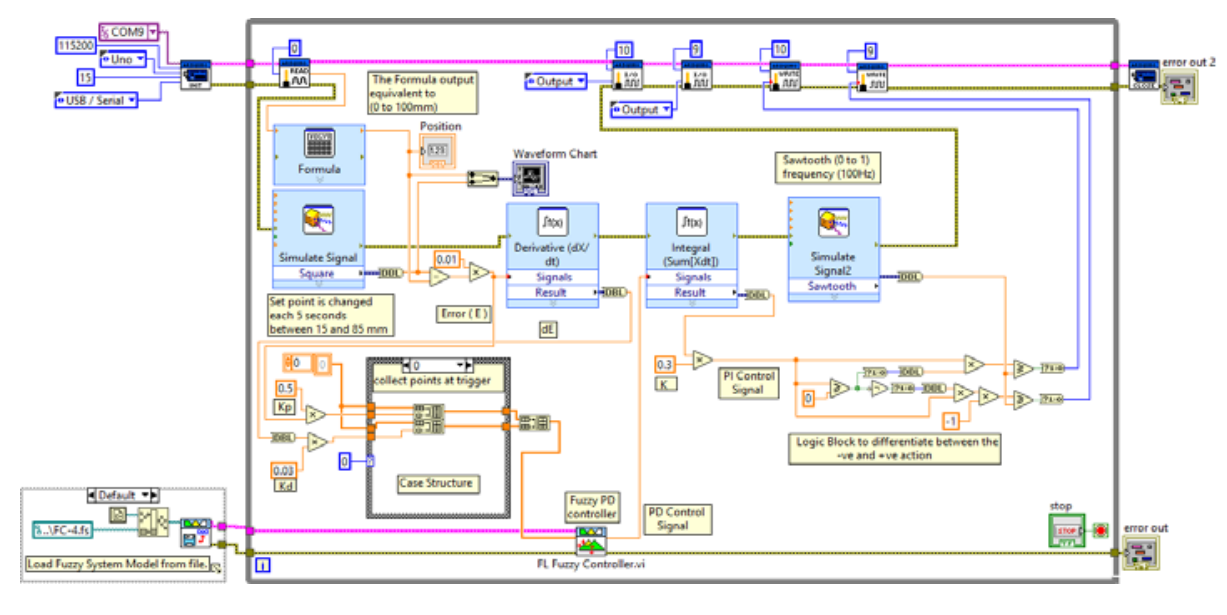

FIG.9. LABVIEW Program of FuZzy PI CONTROLLER

\section{Results and Conclusions}

In this research a pneumatic servo system (PSS) was designed and implemented using cheap 5/3 way CDCV of two solenoids instead of expensive servo or proportional valves. The CDCV was driven using pulse width modulation (PWM) technique, which was generated in the LabVIEW program and send to the CDCV via Arduino uno microcontroller board. 
In this work PWM at 50,70,90,100 and $110 \mathrm{~Hz}$ frequencies with 4.5, 5 and 5.5bar pressure and different gains were critically designed to examine the effect of changing the pressure and frequency of the system response. A number of curves that represent the system responses were taken from the experimented system as shown in Figures-10, 11, 12, 13 and 14, respectively.

Figure-10 exhibit the response of PWM action at $50 \mathrm{~Hz}$ frequency, with $4.5 \mathrm{bar}$ pressure. It is clear that it is unaccepted, since it includes high ripple amplitude where it looks like unstable system. Increasing the PWM frequency to $70 \mathrm{~Hz}$ gave us the response shown in Figure- 11 where the ripple amplitude was decreased but still unaccepted. Increasing the PWM frequency to $90 \mathrm{~Hz}$ gave us the response shown in Figure-11 where the ripple amplitude was decreased but still unaccepted. Many experiments were done by in increasing the PWM frequencies at same applied pressure (4.5bar). It is concluded that increasing PWM frequency decreases the ripple amplitude (i.e. getting smoother response). Accepted responses were obtained with PWM frequencies $90 \mathrm{~Hz}$ and up. Thus we concluded that obtaining acceptable results requires using PWM technique at $90 \mathrm{~Hz}$ or up frequency. Example of that is explained in Figure-12 where acceptable response was obtained (fast response, small overshoot and less than 5\% steady state error) using PWM technique at $100 \mathrm{~Hz}$ frequency and $4.5 \mathrm{bar}$.

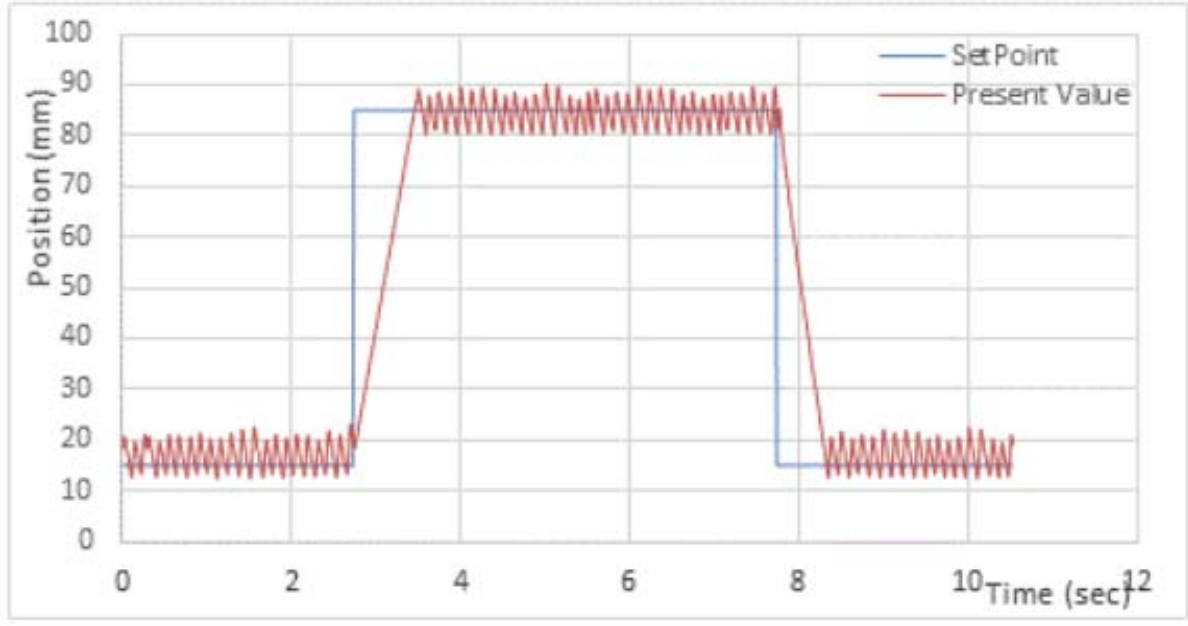

FIG.10. PWM WITH $50 \mathrm{~Hz} / 4.5$ BAR

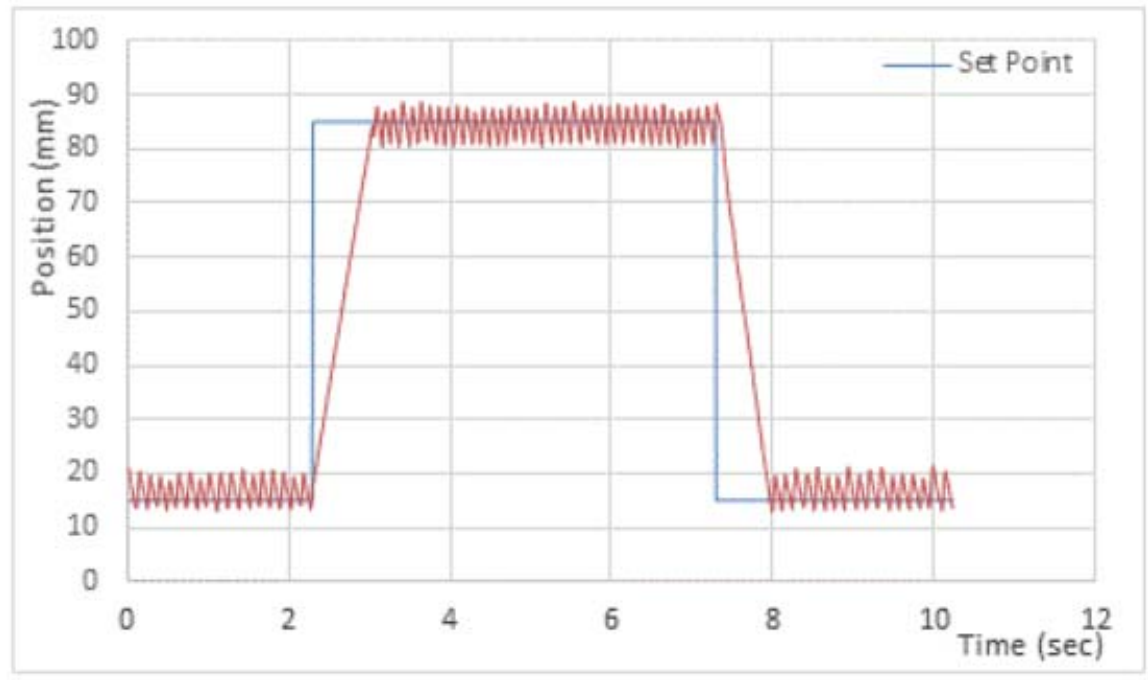

FIG.11. PWM WITH 70 Hz / 4.5 BAR

Different applied pressures using PWM at same frequency $(100 \mathrm{~Hz})$ were experimented. Figure-12, 13 and 14 clearly illustrate the responses of PWM action at a frequency $100 \mathrm{~Hz}$ with $4.5,5$ and $5.5 \mathrm{bar}$ 
pressure, respectively. It can be concluded that increasing the applied pressure decreases the rising time but increases the ripple amplitude. So, to get an acceptable pneumatic servo system using PWM technique, $90 \mathrm{~Hz}$ or up frequency should be used with pressure chosen experimentally since it is affected by the applied load.

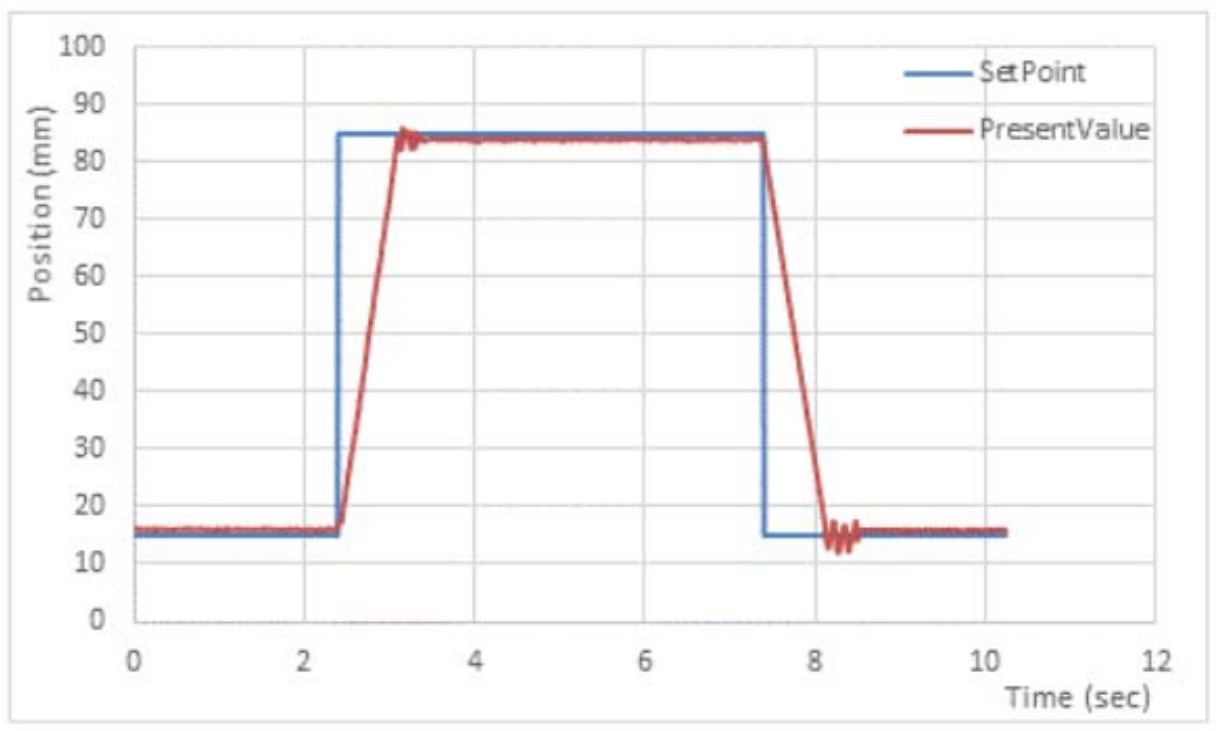

FIG.12. $100 \mathrm{~Hz} / 4.5 \mathrm{BAR}$

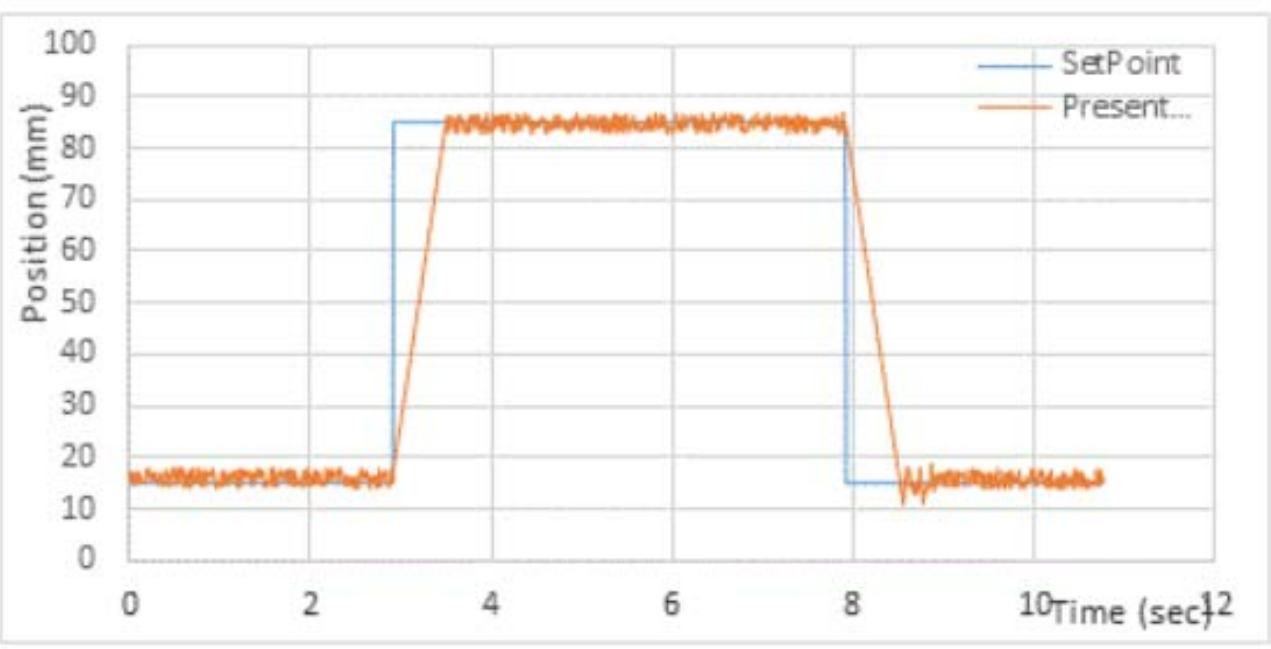

FIG.13. $100 \mathrm{~Hz} / 5 \mathrm{BAR}$ 


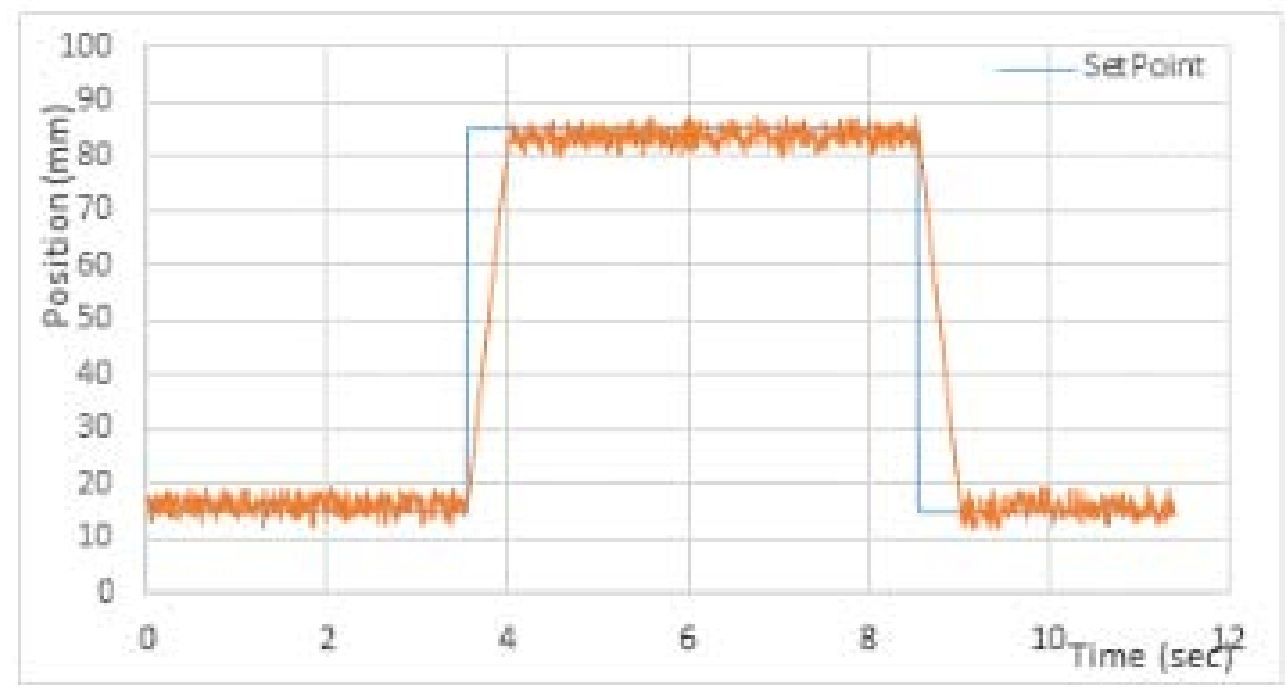

FIG.14. $100 \mathrm{~Hz} / 5.5 \mathrm{BAR}$

\section{REFERENCES}

[1] J. Falcao Carneiro and F. Gomes de Almeida "A high-accuracy trajectory following controller for pneumatic devices" Springer-Verlag London Int J Adv Manuf Technol DOI 10.1007/s00170-011-3695-6 (2011).

[2] B. Varseveld and M. Bone "Accurate Position Control of a Pneumatic Actuator Using On/Off Solenoid Valves" IEEE/ASME transaction on mechatronics, vol. 2, No. 3, September (1997).

[3] S.Hodgson1, M.Tavakoli, M.Tu Pham and A.Leleve "Dynamical Model Averaging and PWM Based Control for Pneumatic Actuators" International Conference on Robotics and Automation, May 2014, Hong Kong, China. IEEE, pp.4798 - 4804, (2014).

[4] M.Hirano, K.Sakaki, T.Fujita, K.kawashima and T.Kagawa "Control System Design of A Pneumatic Servo System Considering the Dynamic Characteristics of the Servo Valve" Proceedings of the 7th JFPS International Symposium on Fluid Power, TOYAMA 2008 September 15-18, (2008).

[5] J. Falcao Carneiro and F. Gomes de Almeida “A Neural Network Based Nonlinear Model of a Servopneumatic System” ASME Journal of Dynamic Systems, Measurement, and Control, Vol. 134 March (2012).

[6] S.Riachy, M.Ghanes "A Nonlinear Controller for Pneumatic Servo Systems Design and Experimental tests" IEEE/ASME transactions on mechatronics, (2013).

[7] M.Smaoui, X.Brun and D.Thomasset "Systematic control of an electropneumatic system Integrator back stepping and sliding mode control" IEEE/ASME Transactions on Control Systems Technology, Institute of Electrical and Electronics Engineers, vol.14, pp.905913, (2006).

[8] X.Shen, Jianlong Zhang, J. Barth and M.Goldfarb "Nonlinear Model-Based Control of Pulse Width Modulated Servo Pneumatic Systems" ASME, Journal of Dynamic Systems, Measurement, and Control, Vol. 128 / 663, September (2006).

[9] H. Fawaz, and A. M. Abdul Aziz "Position Control of a Pneumatic Actuator using Digital Valves and Fuzzy PI Controller" International Journal of Mechanical \& Mechatronics Engineering IJMME-IJENS Vol:16 (2016).

[10] Y. Maolin ,X.Weiqing, and L.Jie "Expansion Energy Used Pneumatic Booster" Chines Journal of Mechanical Engineering, May 16, (2012).

[11] E.Richer and Y.Hurmuzlu "A High Performance Pneumatic Force Actuator System Part 1 - Nonlinear Mathematical Model" ASME Journal of Dynamic Systems Measurement and Control, Vol. 122, No.3, pp. 416-425, February 12, (2001). 